\title{
nature
}

\section{A cautionary guide to university rankings}

Shifts in this year's college rankings from US News \& World Report tell us a little about quality and a lot about the essentially arbitrary nature of the exercise.

T here will no doubt be dancing in the streets of Pasadena this week, following the news that the California Institute of Technology has leapfrogged above the usual Ivy League contenders to top the college rankings presented each year by the news magazine US News \& World Report.

Such a party is due not because of the significance of the event itself — which is slight — but because everyone at Caltech seems to need a break. According to US News, classes at the science and engineering school can often last until 2 a.m. One inmate describes Caltech life thus: "Grades, social life, sleep: pick two." The magazine had to delve back 15 years for an example of interesting non-curricular activity at the school. The example in question was the 1984 Rose Bowl football game between UCLA and Illinois, at which Caltech undergraduates - lacking a football team of their own - reportedly hacked into the scoreboard to make it read "Caltech 38, MIT 9".

On the surface, at least, Caltech officials are managing to keep their excitement under control. "I don't think the rankings are terribly meaningful, but they are useful," vice-provost David Goodstein told US News. "It's like winning the Rose Bowl. It doesn't change the school or its characteristics, but it's a nice thing to have. I don't doubt that we'll use it in advertising to attract students and impress donors."

Potential students are certainly paying attention. For high-school students spending the end of their summer vacation in what is now the traditional way - in the basement, playing computer games and surfing the web - all roads now lead to http://www.usnews.com/ usnews/edu/college/corank.htm. The site has been swamped beneath the weight of visitors.

When they get to the site, they will discover that US News has explained and qualified its findings with admirable forthrightness. It points out, for example, that Caltech has surpassed last year's joint winners - Harvard, Princeton and Yale - chiefly on account of changes not in school performance, but in study methodology.

This year, instead of simply ranking the schools in order of success in each category - for example, amount spent per student — and adding up the rankings, US News weights the institutional scores to reflect the extent of each school's achievements in each category. Caltech, for example, spends an astonishing \$192,000 per student, more than twice as much as any of its rivals. It has a student-to-faculty ratio of 3:1, against 8:1 at Harvard, for example. By giving weight to Caltech's overwhelming resource advantage, the new technique has propelled the smaller school into pole position.

Until next year, that is, when fresh methodological alterations will no doubt give US News a new winner and a fresh blast of publicity. Changing the method is good: if it stayed the same, the rankings probably would too, and where are the headlines in that? In any case, Nature recommends that the youth of America should pause for a while before making that fateful selection. Next month, the Princeton Review will publish its own highly scientific "party school" rankings, which are at least based on a survey of real students. Last year, the State University of New York at Albany came top, whereas Caltech was nowhere to be seen.

\section{Scandal at the Exploratory}

\section{A heap of public money may be misdirected unless the developers of a new science centre see sense.}

Infuriatingly for some, many members of the public don't want to have their relaxation interrupted by tutorials on scientific principles. That's why nobody expects the media to devote much space or airtime to lectures about genes, electromagnetic radiation or the immune system, all of which are relevant to contentious areas of technology. And all of us - especially if accompanied by children - know the sensation after an hour spent in a museum that the series of displays and explanations is falling into an increasingly enervated cortex.

All credit, then, to those who slip a little appreciation — or possibly even understanding - of science into potentially unreceptive individuals by hands-on involvement in displays. Two of the most notable centres are the Exploratorium in San Francisco, California, and the Exploratory in Bristol, England, which is probably the leading example in Europe. Visit either and you will see a throng of adults and children almost unwittingly exploring the laws of electricity, magnetism and optics, encountering the luminescent traces of quantum chemistry, or learning about human physiology. The level of explanation may not always be ideal, but the 'plores' triumphantly embody an approach that needs to be preserved. They communicate the fundamentals of science, rather than its applications or implications, by engaging the visitor.

Scandalously, the Bristol Exploratory will close at the beginning of next month (see page 804). Having been used as the basis of a success-

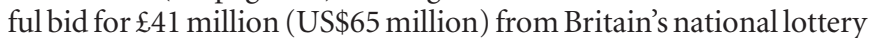
to build a new science centre, to be called "Explore at Bristol", and having set aside its own fund-raising efforts to support the new centre as, not least, its future home, the Exploratory finds itself out in the cold and without the funds required to continue. Those visiting a preview in Bristol of what the new centre will contain will see their worst fears confirmed: the organizers have settled for high-tech, screen-based demonstrations that make minimal effort to engage and stimulate the mind, and provide little explanation of scientifically shallow displays.

It is essential that scientific substance be incorporated into the new centre. Although it needs to have a broader appeal than a solely hands-on science centre can provide, Explore should incorporate the philosophy and exhibits of the Exploratory, so that the ideal of promoting understanding through fun can be sustained. Anything less would be to throw away a gem of scientific culture. 